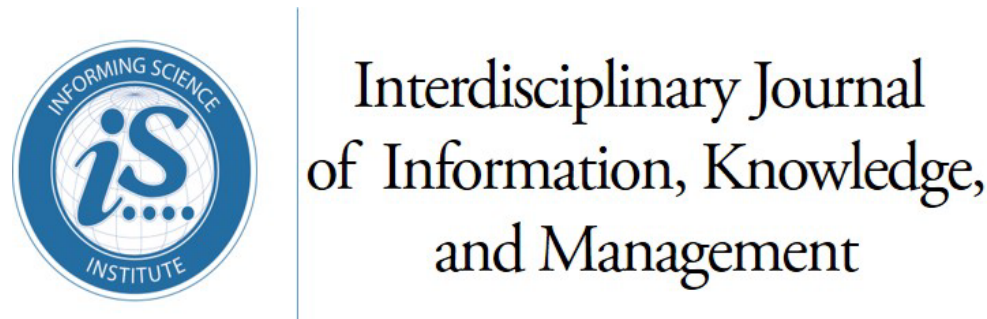

An Official Publication

of the Informing Science Institute

InformingScience.org

IJIKM.org

\title{
Volume 13, 2018 \\ EXPLORING PERCEPTIONS OF BITCOIN AdOPTION: THE SOUTH AFRICAN VIRTUAL COMMUNITY PERSPECTIVE
}

\author{
Aiden Walton \\ Kevin Johnston* \\ * Corresponding author
}

University of Cape Town, Cape

Town, South Africa

University of Cape Town, Cape

Town, South Africa

WLTAID001@,myuct.ac.za

Kevin.johnston@uct.ac.za

\section{ABSTRACT}

Aim/Purpose

This paper explored the factors (enablers and barriers) that affect Bitcoin adoption in South Africa, a Sub-Saharan country with the high potential for Bitcoin adoption.

Background

In recent years, Bitcoin has seen a rapid growth as a virtual cryptocurrency throughout the world. Bitcoin is a protocol which allows value to be exchanged over the internet without a central bank or intermediary. Cryptocurrencies such as Bitcoin are technological tools that arguably can contribute to reducing transactions costs. This paper explored the factors that affect Bitcoin adoption in South Africa, a Sub-Saharan country with the high potential for Bitcoin adoption, as little is known about the factors that affect Bitcoin adoption and the barriers to adoption.

Methodology

A quantitative questionnaire was distributed to South African virtual communities where Bitcoin is a topic of interest, and 237 quantitative responses were received, along with 212 open-ended comments.

Contribution

This research contributes to the body of knowledge in information systems by providing insights into factors that affect Bitcoin adoption in South Africa. It raises awareness of incentives and barriers to Bitcoin adoption at a time when financial literacy is a crucial issue both in South Africa and worldwide.

Findings

The results indicate that perceived benefit, attitude towards Bitcoin, subjective norm, and perceived behavioral control directly affected the participants' intentions to use Bitcoin. Perceived benefit, usefulness, ease of use, and trust-related risk were found to indirectly affect intention to use Bitcoin. Further, it emerges that the barriers to Bitcoin adoption in South Africa consist of the complex nature of Bitcoin and its high degree of volatility.

Accepted by Editor Harry Fulgencio | Received: April 17 3, 2018| Revised: June 1, 2018 | Accepted: June 14, 2018.

Cite as: Walton, A., \& Johnston, K. (2018). Exploring perceptions of bitcoin adoption: The South African virtual community perspective. Interdisciplinary Journal of Information, Knowledge, and Management, 13, 165-182. https://doi.org/10.28945/4080

(CC BY-NC 4.0) This article is licensed to you under a Creative Commons Attribution-NonCommercial 4.0 International License. When you copy and redistribute this paper in full or in part, you need to provide proper attribution to it to ensure that others can later locate this work (and to ensure that others do not accuse you of plagiarism). You may (and we encourage you to) adapt, remix, transform, and build upon the material for any non-commercial purposes. This license does not permit you to use this material for commercial purposes. 
Recommendations Bitcoin can contribute to reducing transactions costs, but factors that affect for Practitioners adoption and the barriers to adoption should be taken into consideration. These findings can inform systems and software developers to develop applications that make managing Bitcoin keys and transacting using Bitcoin less complex and more intuitive for end users.

Recommendations Bitcoin adoption in South Africa is a topic that has not been previously refor Researchers searched. Researchers could research similarities or differences in the various constructs that were used in this research model.

Impact on Society South African Bitcoin users consider it as a universal currency that makes crossborder payments cheaper. A large number of refugees and workers in South Africa make regular payments across borders. Bitcoin could reduce the costs of these transfers.

Future Research Future research could explore Bitcoin (and other cryptocurrencies) adoption in other developing countries. Researchers could look at factors that influence cryptocurrency adoption in general. The factors affecting adoption of other cryptocurrencies can be compared to the results of this study, and similarities and differences can thus be identified.

Keywords Bitcoin, cryptocurrency, virtual community, virtual investment community, South Africa

\section{INTRODUCTION}

Bitcoin is the most widely adopted cryptocurrency. Bitcoin is a "protocol for exchanging value over the internet without an intermediary" (Wan \& Hoblitzell, 2014a, p. 4). A cryptocurrency is a form of digital currency that relies on cryptographic methods (Farell, 2015). It has been noted that the use of Bitcoin is growing at a fast rate, as several online retailers are now accepting bitcoins as a means of payment for goods and services (Berger, 2016). Clegg (2014) argues that Bitcoin will be the transformation of financial behavior in developing economies. According to Manyika, Lund, Singer, White, and Berry (2016), Bitcoin offers a means of improving the lives of individuals in the developing world by providing access to savings and credit facilities. As such, the Sub-Saharan Africa is the region where Bitcoin has the greatest adoption potential (Hileman (2015). Yet, there still lack of knowledge about Bitcoin adoption in Sub-Saharan Africa. In South Africa, the use of bitcoins as a medium of exchange is not yet widespread (Berger, 2016). Therefore, this research seeks to identify the factors that affect Bitcoin adoption, as well as the barriers to Bitcoin adoption, in South Africa. To achieve such aim, the following research questions are investigated: (1) what are the factors that influence Bitcoin adoption by South African virtual communities and virtual investment communities' members? (1.1) what are the perceived benefits and risks of Bitcoin adoption for South African members of virtual communities and virtual investment communities? (1.2) What are the perceived barriers to Bitcoin adoption for South African members of virtual communities and virtual investment communities?

This paper is based on a study by Lee (2009) which looks at factors influencing the adoption of internet banking. It is believed that, as with internet banking adoption, Bitcoin adoption involves the acceptance of an innovative technology along with the effects of social phenomena and personal characteristics (Bashir, Strickland, \& Bohr, 2016; Garcia, Tessone, Mavrodiev, \& Perony, 2014; Grinberg, 2011; Lee, 2009). This descriptive research used an online questionnaire for data collection from 237 South African members of virtual communities (VCs) and virtual investment communities (VICs). The paper is organized as follows: it commences with an overview of Bitcoin. Then the adopted theoretical framework is presented, followed by the formulation of hypothesis. The subse- 
quent section outline of the research method, followed by the presentation of the findings of the analysis and the discussion of results. The paper concludes with the highlight of the paper contributions.

\section{LITERATURE REVIEW}

Bitcoin is a "protocol for exchanging value over the internet without an intermediary" (Wan \& Hoblitzell, 2014a, p. 4). It is the most widely adopted cryptocurrency, a digital currency that relies on cryptographic methods to regulate the generation, verification and transaction between two or more parties (Farell, 2015; Kazan, Tan, \& Lim, 2015). A digital currency refers to a currency that is stored in an electronic ledger (Chuen, 2015). In the Bitcoin protocol, electronic payments are made by generating transactions, which transfer Bitcoin coins between Bitcoin users (Gervais, Capkun, Capkun, \& Karame, 2014). Bitcoins are generated through the process of mining as depicted in Figure 1 showing the complete overview of the Bitcoin protocol (Wan \& Hoblitzell, 2014a).



Figure 1: How Bitcoin works (Wan \& Hoblitzell, 2014a).

The Bitcoin Market Potential Index (BMPI), presented in Figure 2, shows that Sub-Saharan Africa is the region where Bitcoin has the greatest adoption potential (Hileman, 2015). BMPI is a composite indicator that evaluates where Bitcoin has the most and least potential for adoption by measuring Bitcoin's perceived usefulness (Hileman, 2015). Perceived usefulness is affected by perceived ease of use (Lee, 2009).

However, the literature review shows that most of the existing research concerning Bitcoin focus on developed countries, with none of the papers dealing with perceptions of users in Sub-Saharan Africa where Bitcoin is a topic of interest amongst the virtual community. A virtual community (VC) is a group of individuals who share information surrounding a common interest; the sharing of information is supported by information technology and guided by norms (Gu, Konana, Rajagopalan, \& Chen, 2007; Shang, Chen, \& Chen, 2013). According to Shang et al. (2013), information value and social value are the two main areas in which VCs provide value to their members. MyBroadband is an example of a popular South African virtual community. A Virtual investment community (VIC) is a subset of VC that focuses on stock-related topics (Campbell \& Cecez-Kecmanovic, 2011; Meyerindricks, Hooper, \& Johnston, 2016). VICs provide an environment where members can share, dis- 
cuss, and evaluate stock-related information (Campbell \& Cecez-Kecmanovic, 2011; Gu et al., 2007). VICs can be in the form of financial portals (e.g., Fin24 and Yahoo Finance) or message boards (e.g., PlatinumWealth.co.za) (Gu et al., 2007). Perceived usefulness, perceived ease of use, perceived benefits, and perceived risks all influence attitude towards a technology (Lee, 2009). Horst, Kuttschreuter, and Gutteling, (2007) found that perceived usefulness was the main determinant of the intention to use electronic government services. "Risk perception, personal experience, perceived behavioural control and subjective norm were found to significantly predict the perceived usefulness of electronic services in general, while trust in e-government was the main determinant of the perceived usefulness of e-government services" (Horst et al., 2007, p.1838). A person's attitude determines their behavioural intention to use technology (Antonius, Xu, \& Gao, 2015).

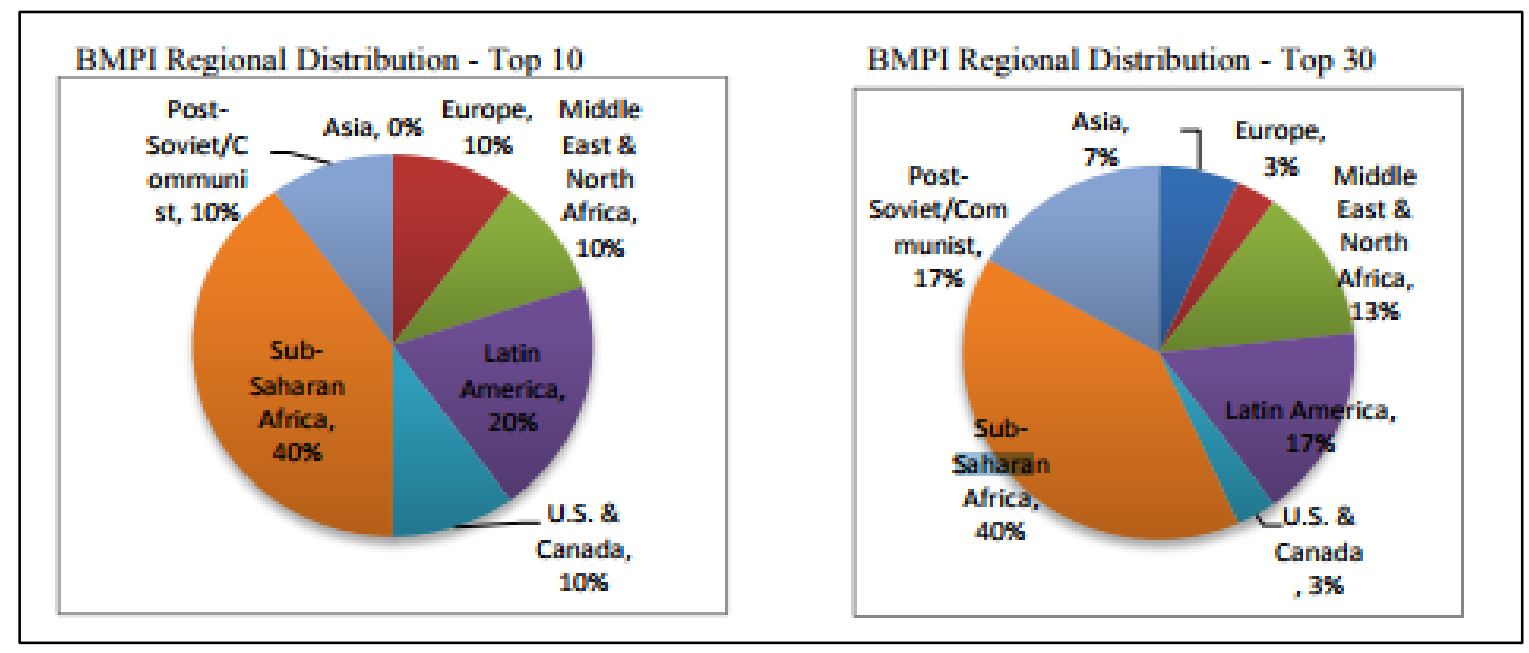

Figure 2: Top 10 and Top 30 BMPI regional distributions (Hileman, 2015).

The literature shows that Bitcoin is still a new technology (Clegg, 2014; Hileman, 2015). According to Lee (2009), the adoption of new technology is influenced by many factors including the perceived benefits, perceived risks, and ease of use. Baur, Bühler, Bick, and Bonorden (2015) found that most stakeholders perceived Bitcoin's ease of use as relatively low. Literature reviewed identified anonymity, security, costs, speculative opportunities and transaction irreversibility as the perceived benefits of adopting Bitcoin (Beer \& Weber, 2015; Dupont \& Squicciarini, 2015; Gao, Clark, \& Lindqvist, 2016; Gentilal, Martins, \& Sousa, 2017; Glaser, Zimmermann, Haferkorn, Weber, \& Siering, 2014; Hur, Jeon, \& Yoo, 2015; Ly, 2013). Bitcoin's pseudo-anonymous and decentralized nature can result in trust issues amongst users, in terms of illicit use and cyber-attacks (Bohr \& Bashir, 2014; Sas \& Khairuddin, 2017). Möser, Böhme, and Breuker (2014) argue that recipients have to accept a risk of invalidation while holding Bitcoins, thus accepting Bitcoins from one party will require a trust relationship between the payee and the payer. According to Sas and Khairuddin (2017), the main security challenges that Bitcoin users face is the risk of insecure transactions and dealing with dishonest traders.

Table 1 presents the factors and their relevant determinants which emerged from the literature, and the Hypotheses they relate to - the Hypotheses are detailed at the end of the literature review. 
Table 1: Factors which emerged from the literature and the Hypotheses they relate to

\begin{tabular}{|c|c|c|c|}
\hline Factors & Determinants & References & Hypotheses \\
\hline $\begin{array}{l}\text { Perceived } \\
\text { usefulness }\end{array}$ & $\begin{array}{l}\text { Potential for adop- } \\
\text { tion, ease of use }\end{array}$ & $\begin{array}{l}\text { Hileman, 2015, Horst, Kuttschreuter, \& Gut- } \\
\text { teling, 2007; Lee, } 2009 .\end{array}$ & H1 \& H5 \\
\hline Attitude & $\begin{array}{l}\text { Perceived useful- } \\
\text { ness, ease of use, } \\
\text { benefits and risks }\end{array}$ & Antonius, Xu, \& Gao, 2015; Lee, 2009. & $\mathrm{H} 2$ \\
\hline $\begin{array}{l}\text { Subjective } \\
\text { norm }\end{array}$ & Perceived intention & $\begin{array}{l}\text { Horst, Kuttschreuter, \& Gutteling, 2007; Lee, } \\
2009 .\end{array}$ & H3 \\
\hline $\begin{array}{l}\text { Perceived } \\
\text { behavioural } \\
\text { control }\end{array}$ & $\begin{array}{l}\text { Control beliefs } \\
\text { about resources and } \\
\text { opportunities }\end{array}$ & $\begin{array}{l}\text { Horst, Kuttschreuter, \& Gutteling, 2007; Lee, } \\
2009 .\end{array}$ & $\mathrm{H} 4$ \\
\hline $\begin{array}{l}\text { Perceived } \\
\text { ease of use }\end{array}$ & Ease of use & $\begin{array}{l}\text { Baur, Bühler, Bick, \& Bonorden, 2015; Lee, } \\
\text { 2009; Wan \& Hoblitzell, 2014b. }\end{array}$ & H6 \& H7 \\
\hline $\begin{array}{l}\text { Perceived } \\
\text { benefits }\end{array}$ & $\begin{array}{l}\text { Anonymity, security, } \\
\text { costs, speculative } \\
\text { opportunities, } \\
\text { transaction irrevers- } \\
\text { ibility }\end{array}$ & $\begin{array}{l}\text { Beer \& Weber, 2015; Dupont \& Squicciarini, } \\
\text { 2015; Gao, Clark, \& Lindqvist, 2016; Gentilal, } \\
\text { Martins, \& Sousa, 2017; Glaser, Zimmermann, } \\
\text { Haferkorn, Weber, \& Siering, 2014; Hur, Jeon, } \\
\text { \& Yoo, 2015; Ly, 2013. }\end{array}$ & H8 \& H9 \\
\hline \multirow[t]{2}{*}{$\begin{array}{l}\text { Perceived } \\
\text { Risks }\end{array}$} & Trust-related risks & $\begin{array}{l}\text { Bohr \& Bashir, 2014; Möser, Böhme \& } \\
\text { Breuker, 2014; Sas \& Khairuddin, } 2017 .\end{array}$ & $\begin{array}{l}\text { H12, H13 \& } \\
\text { H14 }\end{array}$ \\
\hline & $\begin{array}{l}\text { Security-related } \\
\text { risks }\end{array}$ & Sas \& Khairuddin, 2017. & H10 \& H11 \\
\hline
\end{tabular}

This research follows the methodology employed by Lee (2009) which looked at factors influencing the adoption of internet banking. Bitcoin adoption, like the adoption of internet banking, involves the acceptance of an innovative technology, along with social systems and personal characteristics (Bashir et al., 2016; Garcia et al., 2014; Grinberg, 2011; Lee, 2009). As with Lee (2009), this research employs two research streams, the information technology adoption theory and perceived risk theory, to develop the research model and hypotheses.

\section{TECHNOLOGY ACCEPTANCE MODEL (TAM)}

For TAM, an individual's behavioral intention to use a system is determined by two factors: perceived usefulness and perceived ease of use (Diatmika, Irianto, \& Baridwan, 2016). Perceived usefulness is defined as "the degree to which a person believes that using a particular system would enhance his or her job performance" (Davis, 1989, p. 320). Perceived ease of use is the "degree to which a person believes that using a particular system would be free of effort" (Davis, 1989, p. 320). TAM examines the relationship between perceived ease of use and perceived usefulness between system characteristics (external variables) and the probability of system use (Legris, Ingham, \& Collerette, 2003). There are various factors that affect perceived usefulness and intention to use, namely, voluntariness, experience, subjective norm, image, job relevance, output quality and result demonstrability (Diatmika et al., 2016). Legris et al. (2003) criticize TAM saying that its results are not consistent or clear. They argue that TAM is a useful model but should be integrated into a broader model that explains human and social change processes. Kwon and Chidambaram (2000) agree with this criticism, finding that the model does not explain a considerable portion of variance and that other additional factors should be considered when researching adoption. 


\section{THEORY OF PLANNED BEHAVIOUR (TPB)}

The TPB theorizes that human action is guided by three factors (Ajzen, 1991): (1) beliefs about the likely outcomes of the behaviour and the evaluations of these outcomes (behavioural beliefs); (2) beliefs about the normative expectations of others and motivation to comply with these expectations (normative beliefs); and (3) beliefs about the presence of factors that may facilitate or impede the performance of the behaviour and the perceived power of these factors (control beliefs). According to TPB, intentions to perform particular behaviors can be predicted by an individual's attitudes towards the behavior, subjective norms, and perceived behavioral control (Ajzen, 1991). Perceived behavioral control along with behavioral intention can be used to directly predict behavioral achievement (Ajzen, 1991). Weigel, Hazen, Cegielski, and Hall (2014) found that the three factors that guide human action in TPB are significantly and positively related to information systems adoption propensity.

\section{THE INTEGRATION OF TAM AND TPB}

It is argued that the integration of the theory of planned behaviour (TPB) and the technology acceptance model (TAM), as presented in Figure 3, has better exploratory power than the individual use of either TAM or TPB (Chen, Fan, \& Farn, 2007; Lee, 2009; Lu, Huang, \& Lo, 2010). Previous research has integrated the two models to examine information technology (IT) and e-service acceptance. The integration of TAM and TPB should be comprehensive in examining consumer perception and acceptance of Bitcoin use.

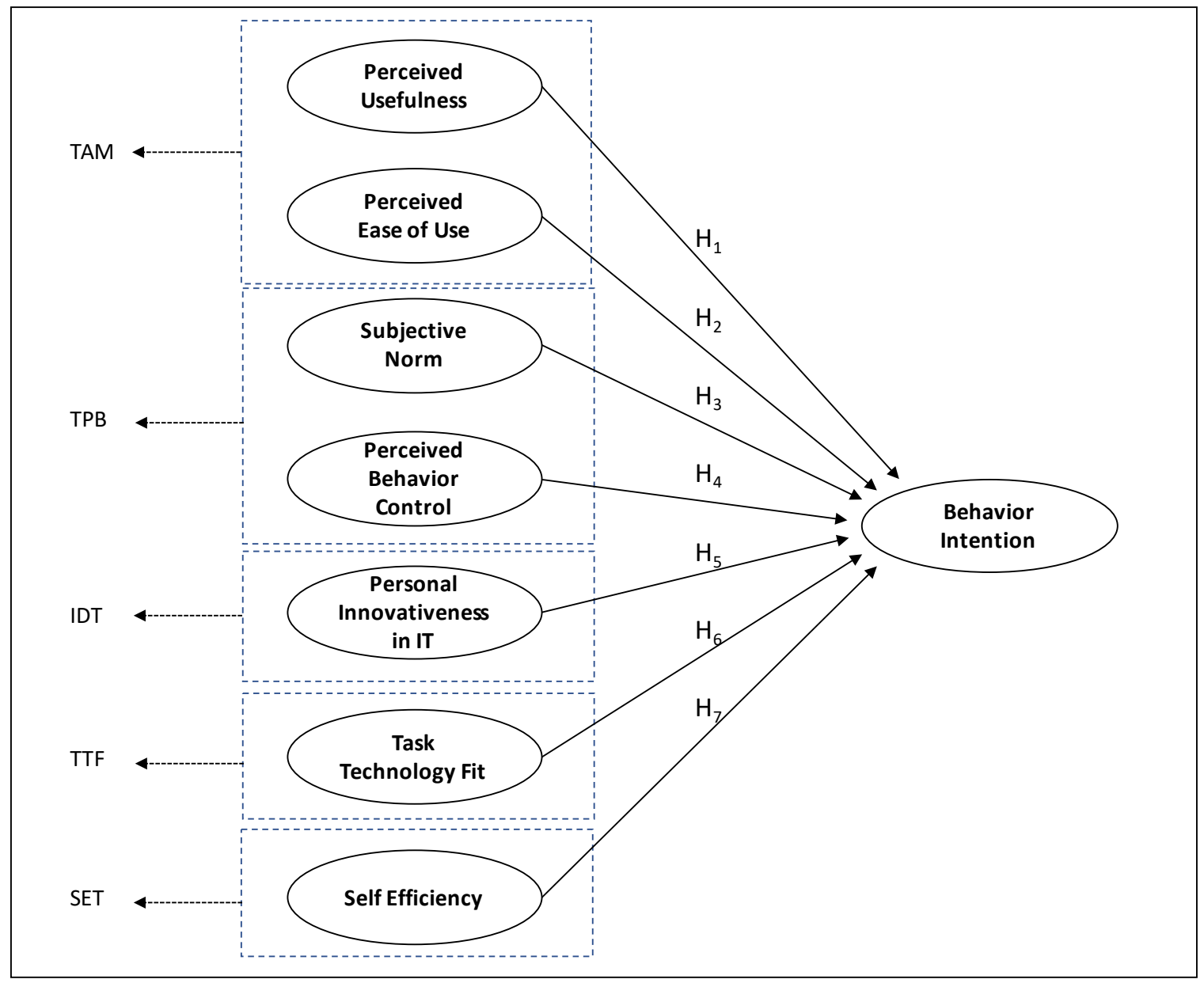

Figure 3: Integration of TPB and TAM (Diatmika, Irianto \& Baridwan, 2016). 
The research model contained the following independent variables: perceived benefits, perceived ease of use, perceived security risks, and perceived trust risks as independent variables. Perceived usefulness, subjective norm, and perceived behavioral control were intervening variables, and intention to use Bitcoin was the dependent variable. The research model, along with the hypothesized relationships, is outlined in Figure 4.

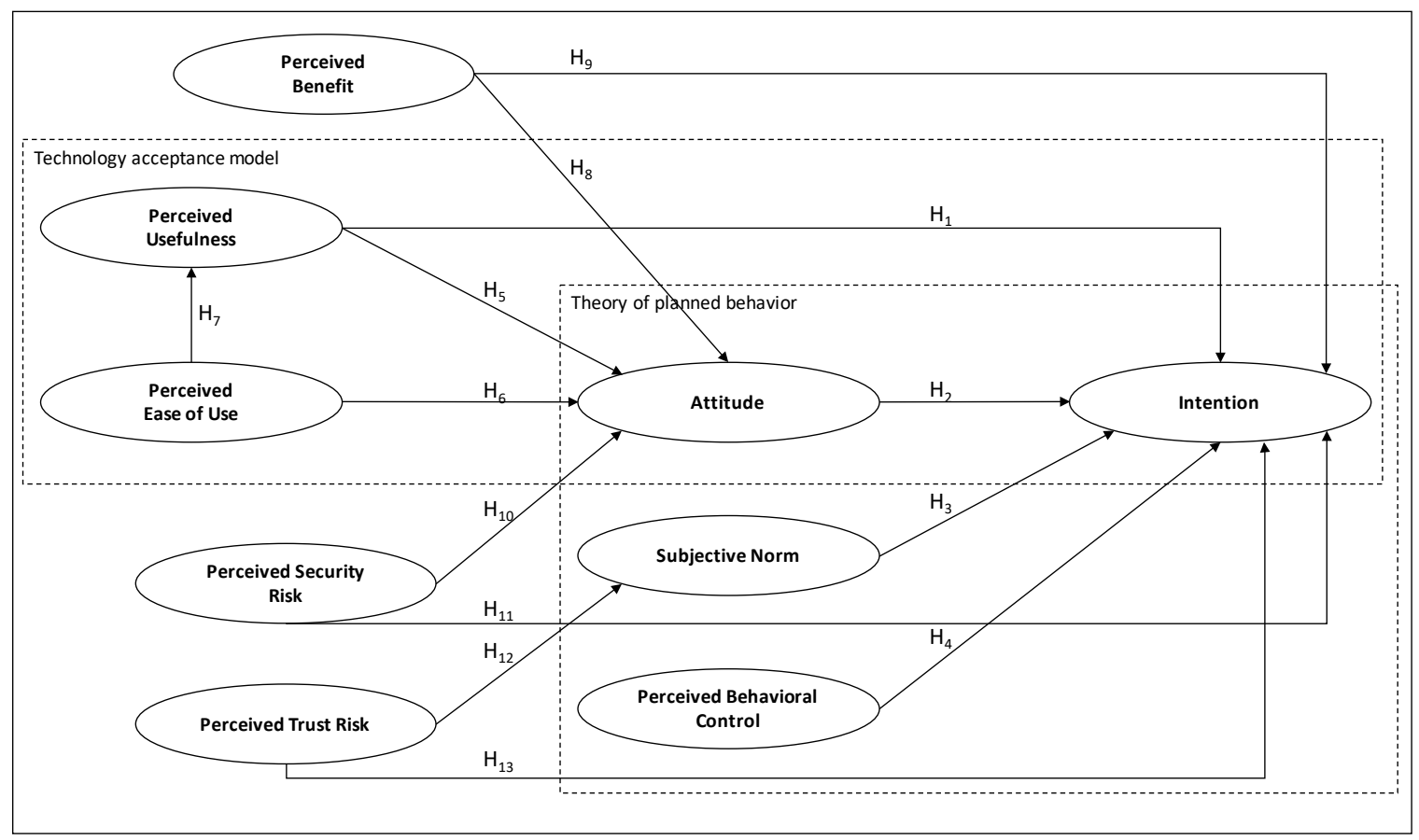

Figure 4: Proposed Research Model. Adapted from Lee (2009).

For the purpose of this research, the following hypotheses were formulated: H1, H2, H5, H6 and H7 based on TAM, and H3 and H4 based on TPB (Lee, 2009), H8, H9, H10, H11, H12, H13 and H14 based on the factors identified in the literature review and presented in Table 1.

H1: Perceived usefulness positively influences the intention to use Bitcoin.

H2: Attitude positively influences the intention to use Bitcoin.

H3: Subjective norm positively influences the intention to use Bitcoin.

H4: Perceived behavioral control positively influences the intention to use Bitcoin.

H5: Perceived usefulness positively influences attitudes towards the use of Bitcoin.

H6: Perceived ease of use positively influences attitudes towards the use of Bitcoin.

H7: Perceived ease of use positively influences the perceived usefulness of Bitcoin.

H8: Perceived benefit positively influences users' attitudes towards the use of Bitcoin.

H9: Perceived benefit has a positive influence on intention to use Bitcoin.

H10: Perceived security risk negatively influences attitude towards Bitcoin.

H11: Perceived security risk negatively influences intention to use Bitcoin.

H12: Perceived trust risk negatively influences subjective norm towards Bitcoin.

H13: Perceived trust risk negatively influences users' intention to use Bitcoin.

H14: Perceived trust risk negatively influences users' attitudes towards the use of Bitcoin. 


\section{RESEARCH METHODOLOGY}

This research uses quantitative and qualitative data collected at the same time and analyzed separately (Saunders, 2011). Such mixed methods approach allows the collection of qualitative data crucial for the explanation of relationships between quantitative variables (Saunders, 2011). Qualitative data shed lights on different aspects of Bitcoin adoption that were not represented in the adopted theoretical framework. Therefore, an inductive approach was used in the qualitative component of the questionnaire to better understand the factors that influence Bitcoin adoption and the barriers to Bitcoin adoption in South Africa. The deductive approach tests existing theory and explains causal relationships between variables (Saunders, 2011) to allow the formulation of hypotheses which evaluated whether factors relating to TPB, TAM, perceived benefits, and perceived risks influenced Bitcoin adoption.

In this descriptive research, all participants answered the survey questions truthfully, and willingly. Care was taken to ensure that all participants reside in South Africa, by examining their IP addresses, and that all participants are familiar with Bitcoin by focusing only on members of South African VCs and VICs, where Bitcoin is a topic of interest. As Schuh and Shy (2016) alert, the majority of consumers who are aware of virtual currencies such as Bitcoin struggle to answer survey questions accurately because of the unfamiliarity with them. Data collection was done through an online questionnaire (see Appendix) distributed electronically to members of South African VCs and VICs. Two VCs namely MyBroadband and Carbonite.co.za were targeted, along with one VIC named PlatinumWealth as they were active in Bitcoin discussion. The Qualtrics survey tool was used to host the questionnaire and collect the results. In total, 237 valid responses were received. Data analysis was done using IBM SPSS Statistics and IBM SPSS Amos. After the survey period, the data was exported to a CSV file and imported into SPSS Statistics for analysis. The data analysis followed a two-step procedure by first examining the measurement model to measure convergent and discriminant validity (Anderson \& Gerbing, 1988), and then examining the structural model to investigate the direction and strength of the relationships between the theoretical constructs (Lee, 2009).

\section{RESULTS AND DISCUSSION OF FINDINGS}

\section{ANALYSIS OF THE MEASUREMENT MODEL}

Three criteria recommended by Fornell and Larcker (1981) were then used to determine convergent validity such as (1) All indicator factor loadings (k) should be significant and be greater than $0.5,(2)$ Construct reliabilities should be greater than 0.8 , and (3) the average variance extracted (the variance captured by the construct in relation to the variance due to measurement error) should exceed 0.5. In order to assess discriminant validity, this research followed Fornell and Larcker's (1981) criterion, which states that the correlation between any two constructs should be lower than the square root of the average variance extracted of items within a construct.

The factor loadings, average variance extracted (AVE), construct reliabilities (CR) and Cronbach alpha scores of the various constructs are presented in Table 2. It emerges that, the factor loading of item PTR3 was 0.45 and thus lower than Fornell and Larcker's (1981) recommendation. The factor loading of PTR3 also contributed to the low AVE of perceived trust risk. A factor loading of 0.40 or more is minimally acceptable and can be considered significant given a sample size of 150 or more (Hair, Black, Babin, Anderson, \& Tatham, 1998). Therefore, PTR3 was maintained for the analysis given that the sample size is greater than 150, and due to the relatively low number of other questionnaire items exploring perceived trust risk, and the acceptable CR and Cronbach alpha values. The AVE of perceived benefits was 0.44 , below the threshold of 0.5 recommended by Fornell and Larcker (1981). This low AVE was largely due to the low factor loading of PB2. an AVE value of 0.4 can be considered acceptable, and provide adequate convergent validity if $\mathrm{CR}$ is above 0.6 , therefore, 
item PB2 was retained given that there were only two other questionnaire items that measured perceived benefit and the CR and Cronbach alpha values were acceptable.

Table 2: Factor loadings and Cronbach Alpha scores

\begin{tabular}{|c|c|c|c|c|c|}
\hline Construct & Item & $\begin{array}{l}\text { Factor } \\
\text { Loading }\end{array}$ & $\begin{array}{l}\text { AV Extract- } \\
\text { ed }\end{array}$ & CR & $\begin{array}{l}\text { Cronbach's } \\
\text { Alpha }\end{array}$ \\
\hline \multirow[t]{2}{*}{ Perceived Usefulness } & PU1 & 0,72 & 0,65 & 0,78 & 0,77 \\
\hline & PU2 & 0,88 & & & \\
\hline \multirow[t]{3}{*}{ Perceived Ease of Use } & PEOU1 & 0,81 & 0,5 & 0,85 & 0,72 \\
\hline & PEOU2 & 0,73 & & & \\
\hline & PEOU3 & 0,55 & & & \\
\hline \multirow[t]{4}{*}{ Attitude } & Attitude1 & 0,84 & 0,57 & 0,91 & 0,85 \\
\hline & Attitude2 & 0,64 & & & \\
\hline & Attitude3 & 0,73 & & & \\
\hline & Attitude4 & 0,79 & & & \\
\hline \multirow[t]{2}{*}{ Perceived Behavioural Control } & PBC1 & 0,93 & 0,57 & 0,7 & 0,69 \\
\hline & PBC2 & 0,51 & & & \\
\hline \multirow[t]{2}{*}{ Intention } & Intention1 & 0,83 & 0,76 & 0,86 & 0,89 \\
\hline & Intention 2 & 0,91 & & & \\
\hline \multirow[t]{3}{*}{ Perceived Benefits } & PB1 & 0,68 & 0,44 & 0,76 & 0,62 \\
\hline & PB2 & 0,54 & & & \\
\hline & PB3 & 0,76 & & & \\
\hline \multirow[t]{2}{*}{ Subjective Norm } & SubjNorm1 & 0,92 & 0,78 & 0,87 & 0,87 \\
\hline & SubjNorm2 & 0,84 & & & \\
\hline \multirow[t]{3}{*}{ Perceived Trust Risk } & PTR1 & 0,89 & 0,44 & 0,81 & 0,67 \\
\hline & PTR2 & 0,57 & & & \\
\hline & PTR3 & 0,45 & & & \\
\hline \multirow[t]{2}{*}{ Perceived Security Risk } & PS1 & 0,76 & 0,66 & 0,79 & 0,79 \\
\hline & PS2 & 0,86 & & & \\
\hline
\end{tabular}

The criterion for discriminate validity was met as shown in Table 3 since the correlations between any construct and the other constructs are less than the square root of the AVE value for the construct. The correlations between the research constructs, with the square roots of the AVE values in bold. 
Table 3: Correlation matrix showing discriminant validity. Diagonal items (in bold) are the square roots of AVE values

\begin{tabular}{|c|c|c|c|c|c|c|c|c|c|}
\hline Construct & $\begin{array}{l}\text { Perceived } \\
\text { Usefulness }\end{array}$ & $\begin{array}{l}\text { Perceived } \\
\text { Ease of } \\
\text { Use }\end{array}$ & Attitude & $\begin{array}{l}\text { Subjective } \\
\text { Norm }\end{array}$ & $\begin{array}{l}\text { Perceived } \\
\text { Behaviour } \\
\text { Control }\end{array}$ & $\begin{array}{l}\text { Intention } \\
\text { to Use }\end{array}$ & $\begin{array}{l}\text { Perceived } \\
\text { Benefit }\end{array}$ & $\begin{array}{l}\text { Perceived } \\
\text { Security } \\
\text { Risk }\end{array}$ & $\begin{array}{l}\text { Perceived } \\
\text { Trust } \\
\text { Risk }\end{array}$ \\
\hline $\begin{array}{l}\text { Perceived } \\
\text { Usefulness }\end{array}$ & 0,81 & & & & & & & & \\
\hline $\begin{array}{l}\text { Perceived } \\
\text { Ease of } \\
\text { Use }\end{array}$ & 0,32 & 0,71 & & & & & & & \\
\hline Attitude & 0,73 & 0,38 & 0,75 & & & & & & \\
\hline $\begin{array}{l}\text { Subjective } \\
\text { Norm }\end{array}$ & 0,40 & 0,20 & 0,45 & 0,88 & & & & & \\
\hline $\begin{array}{l}\text { Perceived } \\
\text { Behaviour } \\
\text { Control }\end{array}$ & 0,41 & 0,41 & 0,50 & 0,28 & 0,75 & & & & \\
\hline $\begin{array}{l}\text { Intention } \\
\text { to Use }\end{array}$ & 0,56 & 0,33 & 0,71 & 0,43 & 0,54 & 0,87 & & & \\
\hline $\begin{array}{l}\text { Perceived } \\
\text { Benefit }\end{array}$ & 0,40 & 0,28 & 0,44 & 0,24 & 0,37 & 0,44 & 0,66 & & \\
\hline $\begin{array}{l}\text { Perceived } \\
\text { Security } \\
\text { Risk }\end{array}$ & $-0,19$ & $-0,20$ & $-0,18$ & $-0,04$ & $-0,26$ & $-0,17$ & $-0,24$ & 0,81 & \\
\hline $\begin{array}{l}\text { Perceived } \\
\text { Trust Risk }\end{array}$ & $-0,30$ & $-0,24$ & $-0,36$ & $-0,21$ & $-0,35$ & $-0,30$ & $-0,29$ & 0,38 & 0,66 \\
\hline
\end{tabular}

\section{ANALYSIS OF THE STRUCTURAL MODEL}

The proposed conceptual model achieved a ratio of chi-square to the degrees of freedom of 12.732 and was significant at $\mathrm{p}=0.001$. This result shows that the proposed research model adequately explained the variance and covariance of the data (Lee, 2009).

Table 4: Demographic Breakdown.

\begin{tabular}{|l|l|l|}
\hline Gender & \multicolumn{2}{l|}{} \\
\hline Male & 226 & $95,4 \%$ \\
\hline Female & 9 & $3,8 \%$ \\
\hline Other & 1 & $0,4 \%$ \\
\hline Prefer not to say & 1 & $0,4 \%$ \\
\hline Age Groups & & \\
\hline $18-24$ & 39 & $16,5 \%$ \\
\hline $25-34$ & 114 & $48,0 \%$ \\
\hline $35-44$ & 56 & $23,6 \%$ \\
\hline $45-54$ & 21 & $8,9 \%$ \\
\hline $55+$ & 7 & $3,0 \%$ \\
\hline Previously used Bitcoin & & $59,1 \%$ \\
\hline Yes & 140 & $40,9 \%$ \\
\hline No & 97 & \\
\hline Previously used another cryptocurrency & & $44,7 \%$ \\
\hline Yes & 106 & $55,3 \%$ \\
\hline No & 131 & \\
\hline
\end{tabular}


Table 4 shows that the 25-34 age group had the greatest portion of respondents (48\%), followed by the 35-44 age group (24\%), and Figure 5 shows that previous Bitcoin use was greatest (by proportion) in the youngest age group (18-24-year olds) at 64\%, and decreased as the age groups became older. Of the respondents, $60 \%$ of $25-34$-year olds had used Bitcoin, along with $52 \%$ of $35-44$-year olds, $48 \%$ of $45-54$-year olds and $43 \%$ of the respondents aged 55 or more.

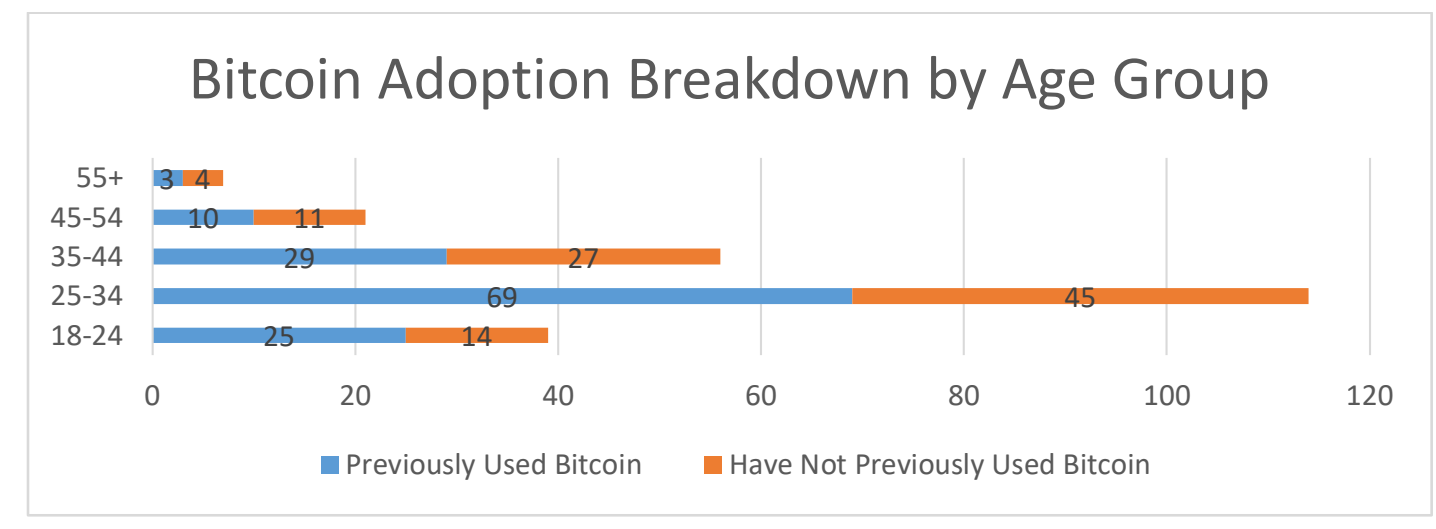

Figure 5: Bitcoin Adoption Breakdown by Age Group.

The hypotheses were tested using a structural equation modeling (SEM) approach which tests the relationships of the constructs identified in the research model (Schumacker \& Lomax, 2004). The confirmatory factor analysis (CFA) model was used as the method to determine construct validity, as recommended by Bagozzi, Yi, and Phillips (1991). The CFA model allowed calculation of the degree of variation in terms of intention to use Bitcoin that is explained by the constructs of the research model. This allows for an analysis of the hypothesized paths shown earlier in Figure 4 and, ultimately, determines whether the identified constructs affect Bitcoin adoption (Lee, 2009).

The results of the structural model as depicted in Figure 6, in which non-significant relationships are represented as dotted lines, H1, H10, H11, and $\mathrm{H} 13$ were rejected, while H2, H3, H4, H5, H6, H7, $\mathrm{H} 8, \mathrm{H} 9$, and $\mathrm{H} 14$ were supported.

Intention to use Bitcoin was predicted by attitude $(\beta=0.52, \mathrm{p}<0.001)$, subjective norm $(\beta=0.12, \mathrm{p}$ $<0.05)$, perceived behavioural control $(\beta=0.25, \mathrm{p}<0.001)$, and perceived benefit $(\beta=0.13, \mathrm{p}<$ 0.05 ) and thus supporting hypotheses 2, 3, 4 and 9 which means the following: Attitude positively influences the intention to use Bitcoin; Subjective norm positively influences the intention to use Bitcoin; Perceived behavioural control positively influences the intention to use Bitcoin; and Perceived benefit has a positive influence on intention to use Bitcoin. Attitude towards Bitcoin was predicted by perceived usefulness $(\beta=0.64, \mathrm{p}<0.001)$, perceived ease of use $(\beta=0.14, \mathrm{p}<0.01)$, perceived benefit $(\beta=0.14, \mathrm{p}<0.01)$, and perceived trust risk $(\beta=-0.14, \mathrm{p}<0.01)$ supporting hypotheses 5, 6, 8 and 14 which means the following: Perceived usefulness positively influences attitudes towards the use of Bitcoin; Perceived ease of use positively influences attitudes towards the use of Bitcoin; Perceived benefit positively influences users' attitudes towards the use of Bitcoin; and Perceived trust risk negatively influences users' attitudes towards the use of Bitcoin. Perceived usefulness of Bitcoin was predicted by perceived ease of use $(\beta=0.32, \mathrm{p}<0.001)$, supporting hypothesis 7 , and subjective norm was predicted by perceived trust risk $(\beta=0.21, \mathrm{p}<0.01)$ supporting hypothesis 12 which means the following: Perceived ease of use positively influences the perceived usefulness of Bitcoin, and Perceived trust risk negatively influences subjective norm towards Bitcoin. 


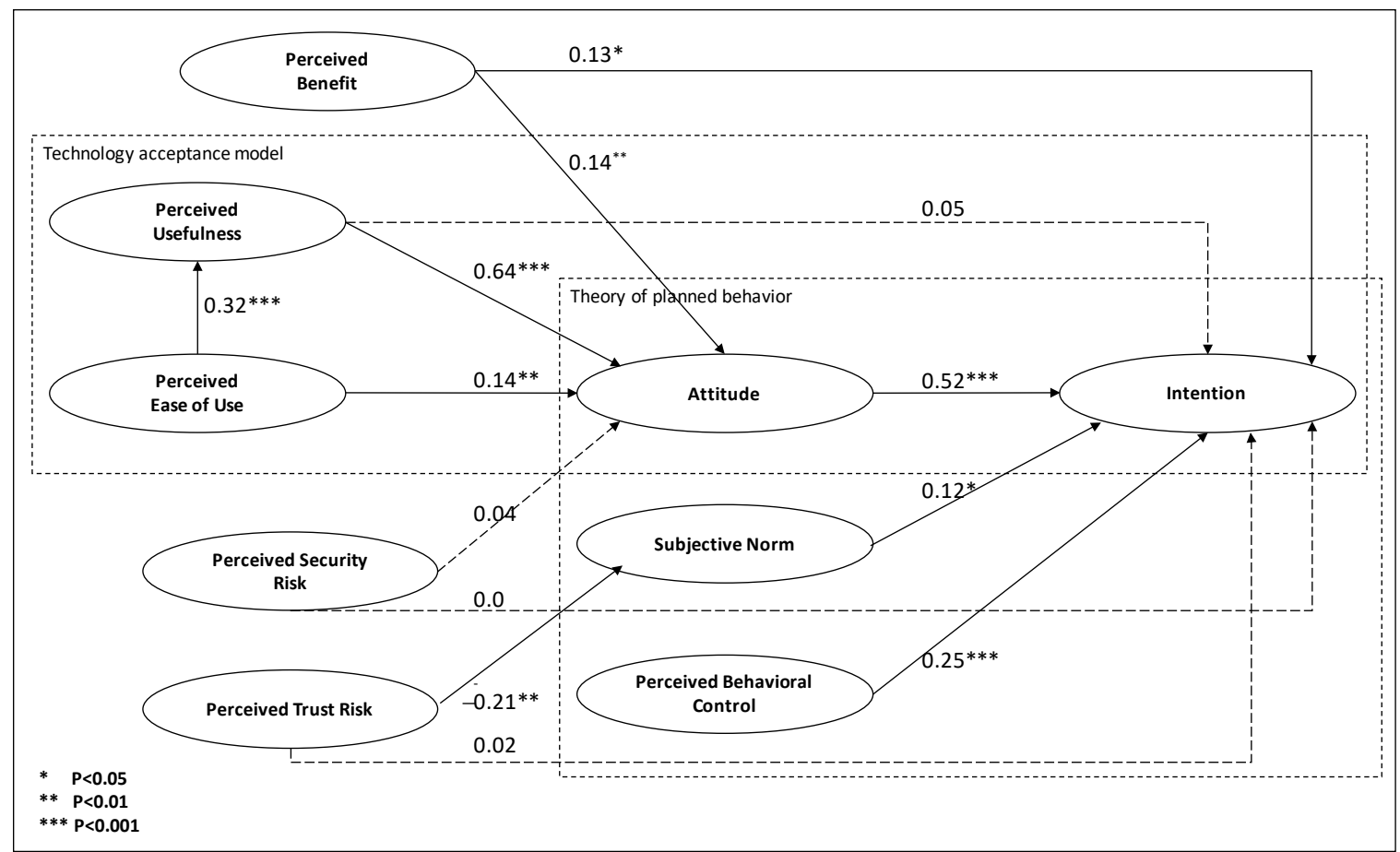

Figure 6: Research Model with Results

Attitude appears to be the greatest influencer of intention to use Bitcoin $(\beta=0.52)$. This research shows that participants' attitude is influenced by the perceptions surrounding trust-related risk, ease of use, usefulness, and benefit.

Perceived usefulness indirectly influences intention to use Bitcoin by influencing consumer attitude towards Bitcoin. The open-ended responses point to investment as a key factor that influenced Bitcoin adoption. This finding agrees with Glaser et al. (2014) that new users tend to regard bitcoin as a speculative asset, rather than as a means of paying for goods or services.

Subjective norm had a slightly positive influence on intention to use Bitcoin $(\beta=0.12)$. Perceived trust risk was found to negatively impact subjective norm. One participant stated that he would use bitcoin because "everyone [they] know has recommended it, especially through Luno [a South African Bitcoin exchange]"

Perceived ease of use indirectly influenced intention to use Bitcoin, by influencing both attitude $(\beta=0.14)$ and perceived usefulness $(\beta=0.32)$. This finding concurs with Wan and Hoblitzell $(2014 \mathrm{~b})$ that Bitcoin will need to address its ease of use in order to experience wider levels of adoption. Participants, particularly the aged, mentioned that they are reluctant to use bitcoin because of its complex nature and is difficult to understand.

Perceived benefit had a direct influence on a consumer's intention to use Bitcoin and an indirect influence on intention by affecting consumer attitude. The most cited reason was the decentralized nature of Bitcoin; "it's a universal currency. It gives you more control over your own money. It cuts out the middleman" (participant). This finding shows that the lack of banks or governmental control in the Bitcoin protocol is seen as one of its benefits for South Africans. This is perhaps due to an increasing lack of trust in South African governments and the frequency of corruption in South Africa (Lannegren \& Ito, 2017). Participants' comments that Bitcoin makes the transfer of money overseas considerably cheaper and easier supports the literature that the decentralized nature of Bitcoin gives rise to lower transaction costs and increased anonymity. 
Walton \& Johnston

Perceived behavioral control $(\beta=0.25)$ informs that participants are more likely to use Bitcoin if they feel that they have the resources, knowledge, and ability to use it and that transacting with Bitcoin is entirely within their control.

Perceived trust risk indirectly influences the intention to use Bitcoin, by influencing both attitude and subjective norm. Participants mentioned the lack of trust as the common reason for not to adopt Bitcoin: "Cryptocurrencies might be secure but I just don't trust hackers, and the bitcoin exchange rate, in my opinion, is very open to manipulation by hackers or bots." and "Most people don't want to be their own bank! They want to rely on a bank to take the risk. If my laptop and safe burn down in a fire, I would lose everything currently, not ideal for the average person." This result supports the literature (Sas \& Khairuddin, 2017) that Bitcoin's pseudo-anonymous and decentralized nature can result in trust issues amongst users, in terms of illicit use and cyber-attacks.

Perceived security risk appears not to have a significant effect on intention to use Bitcoin or attitude towards Bitcoin. The questionnaire items may, therefore, not have been clear enough for the participants to understand. This could have been improved by providing an explanation of the types of security risks relating to Bitcoin (such as users' challenges of handling passwords, hackers' malicious attacks, and failure to recover from human error or malice and dishonest transaction partners).

\section{BARRIERS TO ADOPTION}

Using open-ended question in order to answer the question on barriers to Bitcoin adoption, two factors namely volatility and complexity were identified.

Volatility: Some extracts from the open-ended responses consisted of the following: "[There is] fear that Bitcoin is no more than a short-lived craze", "Not being able to control its value", "No real item supporting the value", "Market is still too volatile, any moment the peak could crash. Thus, the initial value invested could drop a lot", "Potential high volatility", "Volatility. Who really controls the value of bitcoins?", "It can fall just as quickly as it has risen", "Unstable", "Extremely volatile nature means that pricing (relative to fiat currency) can change by a large amount in a small period of time", "Currency value is not stable at all, it's far too volatile!", "Way too volatile", "Volatility in the bitcoin market means that you are not always guaranteed the best price", "The market is volatile - it's not a safe investment, only if you have money you are willing to lose", "The volatile nature of cryptocurrency", "The fluctuation in the market", "Bitcoin is very unstable". Volatility was identified as a key risk in the literature review and is the most cited reason that South Africans do not adopt Bitcoin in this study.

Complexity: Some extracts that cited complexity as a barrier to Bitcoin adoption included the following: "It is not physical", "Bitcoin is complex and will not be easily accepted by the older generation", "...complexity of setting up and understanding...", "[Bitcoin] transactions are complicated and mistakes can be made", "Still complex to fully control one's own [Bitcoin wallet] keys", “... reluctant to learn and adapt", "[I have a] lack of understanding as to how it works", "Difficulty in understanding the currency", "Need to learn how it works", "Difficult to grasp", "At the moment using and understanding bitcoin [is too] difficult for mainstream users". These findings concur with Gao et al. (2016) that likely barriers to Bitcoin adoption are user experience issues and the complex manner in which it is presented. Tools that reduce the complexity of Bitcoin transactions or aid in improving the understanding of the Bitcoin protocol may well, therefore, help to improve Bitcoin adoption (by eliminating key barriers).

\section{CONCLUSION}

Bitcoin adoption in South Africa is a topic that has not been previously researched. South African Bitcoin users consider it as a universal currency which makes cross-border payments cheaper. This research found that Bitcoin adoption in South African VCs and VICs is significantly and directly influenced by the perceived behavioral control, subjective norm, attitude, and perceived benefit of 
Bitcoin. The Perceived ease of use, perceived usefulness, and perceived benefit indirectly affected intention to use Bitcoin by influencing the attitudes of potential users. Perceived trust risk indirectly influenced intention to use Bitcoin by influencing both attitude and subjective norm. The decentralized nature of Bitcoin, together with the lack of any banks or governmental control in the Bitcoin protocol, was seen as a major benefit to the research participants. Bitcoin's ability to offer cheaper, more efficient cross-border transactions was also seen as an important benefit. However, the volatility and trust-related risks such as scams and hacking attempts were seen as the main risks for South African Bitcoin adopters. Further, Bitcoin was seen as difficult to use because it was perceived as being complex to setup, use, and understand. As with Wan and Hoblitzell (2014b), this research argues that Bitcoin will need to address its ease of use in order to experience wider levels of adoption. It emerges that Bitcoin's volatility and complex nature are the dominant barriers to Bitcoin adoption in South African VCs and VICs.

This research contributes to the body of knowledge in information systems by providing insights into factors that affect Bitcoin adoption in the developing world. These findings can inform systems and software developers to develop applications that make managing Bitcoin keys and transacting using Bitcoin less complex and more intuitive for end users.

This study was conducted using an online survey platform, and considered only South African members of virtual communities and virtual investment communities. Although the methods adopted are suitable, further research is needed that use different methods and a more representative sample of the South African population or a different developing country. Future research could identify similarities or differences in the various constructs that were used in this research model. Future research could also explore cryptocurrencies other than Bitcoin, or look at factors that influence cryptocurrency adoption in general. The factors affecting adoption of other cryptocurrencies can be compared to the results of this study, and similarities and differences can thus be identified.

\section{REFERENCES}

Antonius, N., Xu, J., \& Gao, X. (2015). Factors influencing the adoption of enterprise social software in Australia. Knowledge-Based Systems, 73, 32-43. https://doi.org/10.1016/j.knosys.2014.09.003

Ajzen, I. (1991). The theory of planned behavior. Organizational Behavior and Human Decision Processes, 50(2), 179211. https://doi.org/10.1016/0749-5978(91)90020-T

Anderson, J. C., \& Gerbing, D. W. (1988). Structural equation modeling in practice: A review and recommended two-step approach. Psychological Bulletin, 103(3), 411. https://doi.org/10.1037/0033-2909.103.3.411

Bagozzi, R. P., Yi, Y., \& Phillips, L. W. (1991). Assessing construct validity in organizational research. Administrative Science Quarterly, 36(3), 421-458. https://doi.org/10.2307/2393203

Bashir, M., Strickland, B., \& Bohr, J. (2016). What motivates people to use Bitcoin? Paper presented at the International Conference on Social Informatics. https://doi.org/10.1007/978-3-319-47874-6 25

Baur, A. W., Bühler, J., Bick, M., \& Bonorden, C. S. (2015). Cryptocurrencies as a disruption? Empirical findings on user adoption and future potential of Bitcoin and Co. Paper presented at the Conference on e-Business, eServices and e-Society. https://doi.org/10.1007/978-3-319-25013-7 6

Beer, C., \& Weber, B. (2015). Bitcoin - The promise and limits of private innovation in monetary and payment systems. Monetary Policy and the Economy, Q4/2014, 53-66. Available at https://ssrn.com/abstract $=2556800$

Berger, L. L. (2016). Bitcoin exchange transactions: Income tax implications to consider within the South African environment (Doctoral dissertation).

Bohr, J., \& Bashir, M. (2014). Who uses bitcoin? An exploration of the bitcoin community. Paper presented at the 2014 Twelfth Annual International Conference on Privacy, Security, and Trust. https://doi.org/10.1109/PST.2014.6890928 
Campbell, J., \& Cecez-Kecmanovic, D. (2011). Communicative practices in an online financial forum during abnormal stock market behavior. Information \& Management, 48(1), 37-52. https://doi.org/10.1016/j.im.2010.12.003

Chen, C.-D., Fan, Y.-W., \& Farn, C.-K. (2007). Predicting electronic toll collection service adoption: An integration of the technology acceptance model and the theory of planned behavior. Transportation Research Part C: Emerging Technologies, 15(5), 300-311. https://doi.org/10.1016/j.trc.2007.04.004

Chuen, D. L. K. (2015). Handbook of digital currency: Bitcoin, innovation, financial instruments, and big data. Heidelberg: Academic Press.

Clegg, A. G. (2014). Could bitcoin be a financial solution for developing economies? University of Birmingham.

Davis, F. D. (1989). Perceived usefulness, perceived ease of use, and user acceptance of information technology. MIS Quarterly, 13(3), 319-340. https://doi.org/10.2307/249008

Diatmika, I. W. B., Irianto, G., \& Baridwan, Z. (2016). Determinants of behavior intention of accounting information systems based information technology acceptance. Imperial Journal of Interdisciplinary Research, 2(8).

Dupont, J., \& Squicciarini, A. C. (2015). Toward de-anonymizing Bitcoin by mapping users location. Paper presented at the Proceedings of the 5th ACM Conference on Data and Application Security and Privacy. https://doi.org/10.1145/2699026.2699128

Farell, R. (2015). An analysis of the cryptocurrency industry. Wharton Research Scholar, 130.

Fornell, C., \& Larcker, D. F. (1981). Evaluating structural equation models with unobservable variables and measurement error. Journal of Marketing Research, 18(1), 39-50. https://doi.org/10.2307/3151312

Gao, X., Clark, G. D., \& Lindqvist, J. (2016). Of two minds, multiple addresses, and one ledger: Characterizing opinions, knowledge, and perceptions of Bitcoin across users and non-users. Paper presented at the Proceedings of the 2016 CHI Conference on Human Factors in Computing Systems. https://doi.org/10.1145/2858036.2858049

Garcia, D., Tessone, C. J., Mavrodiev, P., \& Perony, N. (2014). The digital traces of bubbles: Feedback cycles between socio-economic signals in the Bitcoin economy. Journal of the Royal Society Interface, 11(99). https://doi.org/10.1098/rsif.2014.0623

Gentilal, M., Martins, P., \& Sousa, L. (2017). TrustZone-backed bitcoin wallet. Paper presented at the Proceedings of the Fourth Workshop on Cryptography and Security in Computing Systems. https://doi.org/10.1145/3031836.3031841

Gervais, A., Capkun, V., Capkun, S., \& Karame, G. O. (2014). Is Bitcoin a decentralized currency? IEEE Security \& Privacy, 3(12), 54-60. https://doi.org/10.1109/MSP.2014.49

Glaser, F., Zimmermann, K., Haferkorn, M., Weber, M. C., \& Siering, M. (2014). Bitcoin - Asset or currency? Revealing users' bidden intentions. Retrieved from https://ssrn.com/abstract $=2425247$

Grinberg, R. (2011). Bitcoin: An innovative alternative digital currency. Hastings Science \& Technology Law Journal, 4, 159-208.

Gu, B., Konana, P., Rajagopalan, B., \& Chen, H.-W. M. (2007). Competition among virtual communities and user valuation: The case of investing-related communities. Information Systems Research, 18(1), 68-85. https://doi.org/10.1287/isre.1070.0114

Hair, J. F., Black, W. C., Babin, B. J., Anderson, R. E., \& Tatham, R. L. (1998). Multivariate data analysis. Upper Saddle River, NJ: Prentice Hall.

Hileman, G. (2015). The Bitcoin market potential index. Paper presented at the International Conference on Financial Cryptography and Data Security. https://doi.org/10.1007/978-3-662-48051-9 7

Horst, M., Kuttschreuter, M., \& Gutteling, J. M. (2007). Perceived usefulness, personal experiences, risk perception and trust as determinants of adoption of e-government services in The Netherlands. Computers in Human Behavior, 23(4), 1838-1852. https://doi.org/10.1016/j.chb.2005.11.003

Hur, Y., Jeon, S., \& Yoo, B. (2015). Is Bitcoin a viable e-business? Empirical analysis of the digital currency's speculative nature. Paper presented at the Thirty Sixth International Conference on Information Systems. 
Kazan, E., Tan, C.-W., \& Lim, E. T. (2015). Value creation in cryptocurrency networks: Towards a taxonomy of digital business models for Bitcoin companies. Paper presented at the 19th Pacific Asia Conference on Information Systems. PACIS 2015.

Kwon, H. S., \& Chidambaram, L. (2000). A test of the technology acceptance model: The case of cellular telephone adoption. Paper presented at the Proceedings of the 33rd Annual Hawaii International Conference on System Sciences, 2000. https://doi.org/10.1109/HICSS.2000.926607

Lannegren, O., \& Ito, H. (2017). The end of the ANC era: An analysis of corruption and inequality in South Africa. Journal of Politics and Law, 10(4), 55-59. https://doi.org/10.5539/ipl.v10n4p55

Lee, M.-C. (2009). Factors influencing the adoption of internet banking: An integration of TAM and TPB with perceived risk and perceived benefit. Electronic Commerce Research and Applications, 8(3), 130-141. https://doi.org/10.1016/j.elerap.2008.11.006

Legris, P., Ingham, J., \& Collerette, P. (2003). Why do people use information technology? A critical review of the technology acceptance model. Information \& Management, 40(3), 191-204. https://doi.org/10.1016/S0378-7206(01)00143-4

Lu, C.-T., Huang, S.-Y., \& Lo, P.-Y. (2010). An empirical study of online tax filing acceptance model: Integrating TAM and TPB. African Journal of Business Management, 4(5), 800-810.

Ly, M. K.-M. (2013). Coining Bitcoin's legal-bits: Examining the regulatory framework for Bitcoin and virtual currencies. Harvard Journal of Law \& Technology, 27(2), 587-608.

Manyika, J., Lund, S., Singer, M., White, O., \& Berry, C. (2016). How digital finance could boost growth in emerging economies. Retrieved from https://www.mckinsey.com/global-themes/employment-and-growth/howdigital-finance-could-boost-growth-in-emerging-economies

Meyerindricks, L., Hooper, V., \& Johnston, K. A. (2016). Determinants of successful virtual investment communities. Paper presented at the CONF-IRM 2016.

Möser, M., Böhme, R., \& Breuker, D. (2014). Towards risk scoring of Bitcoin transactions. Paper presented at the International Conference on Financial Cryptography and Data Security. https://doi.org/10.1007/978-3662-44774-1_2

Sas, C., \& Khairuddin, I. (2017). Design for trust: An exploration of the challenges and opportunities of Bitcoin users. Paper presented at the 2017 CHI Conference on Human Factors in Computing Systems. https://doi.org/10.1145/3025453.3025886

Saunders, M. N. (2011). Research methods for business students (5th ed.). India: Pearson Education Limited.

Schumacker, R. E., \& Lomax, R. G. (2004). A beginner's guide to structural equation modeling (2nd ed.). Mahway, NJ: Lawrence Erlbaum Assosciates, Inc.

Schuh, S., \& Shy, O. (2016). U.S. consumers' adoption and use of Bitcoin and other virtual currencies. Presented at DeNederlandsche Bank Payments Conference "Retail payments: mapping out the road ahead", Amsterdam. Available at https://www.dnb.nl/en/binaries/Session $\% 201 \mathrm{c} \% 20$ Presentation $\% 20$ Schuh tcm 47 342143.pdf?2018061619

Shang, R.-A., Chen, Y.-C., \& Chen, C.-J. (2013). The social and objective value of information in virtual investment communities. Online Information Review, 37(4), 498-517. https://doi.org/10.1108/OIR-06-2011$\underline{0087}$

Wan, T., \& Hoblitzell, M. (2014a). Bitcoin: Fact. Fiction. Future. Retrieved from https://dupress.deloitte.com/dupus-en/topics/emerging-technologies/bitcoin-fact-fiction-future.html

Wan, T., \& Hoblitzell, M. (2014b). Bitcoin’s promise goes far beyond payments. Harvard Business Review blog. Retrieved from https://hbr.org/2014/04/bitcoins-promise-goes-far-beyond-payments

Weigel, F. K., Hazen, B. T., Cegielski, C. G., \& Hall, D. J. (2014). Diffusion of innovations and the theory of planned behavior in information systems research: A meta-analysis. Communications of the Association for Information Systems, 34(1), 619-636. 


\section{APPENDIX}

Table 5: Questionnaire items to evaluate attitude

\begin{tabular}{l|l}
$\begin{array}{l}\text { Item Code } \\
\text { ATT1 }\end{array}$ & Q I think that buying bitcoins is a good idea. \\
$\begin{array}{l}\text { ATT2 } \\
\text { ATT3 }\end{array}$ & I think that using bitcoins for financial transactions would be a wise idea. \\
$\begin{array}{ll}\text { ATT4 } & \text { In my opinion, it is desirable to use Bitcoin as a currency. } \\
\text { Table 6: Questionnaire items to evaluate perceived usefulnes }\end{array}$ \\
$\begin{array}{ll}\text { Item Code } \\
\text { PU1 }\end{array}$ \\
$\begin{array}{ll}\text { PU2 } & \text { I think that owning Bitcoin is advantageous. }\end{array}$ \\
\hline
\end{tabular}

Table 7: Questionnaire items to evaluate subjective norm

\begin{tabular}{l|l} 
Item Code & Questionnaire Item \\
SN1 & People whose opinions are valued to me would think that I should use Bitcoin. \\
SN2 & People who influenced me would think that I should use Bitcoin.
\end{tabular}

Table 8: Questionnaire items to evaluate perceived ease of use

\begin{tabular}{l|l} 
Item Code & Questionnaire Item \\
\hline PEOU1 & I think that learning how to use Bitcoin is easy. \\
\hline PEOU2 & I think that learning how Bitcoin functions as a currency are easy. \\
\hline PEOU3 & I think that it easy to use bitcoins to accomplish my payment tasks. \\
\hline
\end{tabular}

Table 9: Questionnaire items to evaluate perceived benefit

\begin{tabular}{l|l} 
Item Code & \multicolumn{1}{c}{ Questionnaire Item } \\
PB1 & I think that using Bitcoin is more secure than traditional currencies. \\
\hline PB2 & I think that using Bitcoin (over traditional currencies) will cost less. \\
\hline PB3 & $\begin{array}{l}\text { I would use Bitcoin because it provides me with more anonymity than traditional } \\
\text { currencies. }\end{array}$ \\
\hline PB4 & I would use Bitcoin because transactions cannot be reversed.
\end{tabular}

Table 10: Questionnaire items to evaluate perceived behavioural control

\begin{tabular}{|c|c|}
\hline Item Code & Questionnaire Item \\
\hline PBC1 & I think that I would be able to use Bitcoin well for financial transactions. \\
\hline PBC2 & I think that using Bitcoin would be entirely within my control. \\
\hline PBC3 & I think that I have the resources, knowledge, and ability to use Bitcoin. \\
\hline \multicolumn{2}{|c|}{ Table 11: Questionnaire items to evaluate perceived trust risk } \\
\hline Item Code & Questionnaire Item \\
\hline PTR1 & I do not trust Bitcoin because I believe it is often used for illicit activities. \\
\hline PTR2 & $\begin{array}{l}\text { I think that the irreversible nature of Bitcoin transactions may put me at risk of } \\
\text { being scammed. }\end{array}$ \\
\hline PTR3 & $\begin{array}{l}\text { When transferring bitcoins, I am afraid that I will lose money due to careless mis- } \\
\text { takes (such as entering the wrong account number or inputting the wrong amount) }\end{array}$ \\
\hline
\end{tabular}


Table 12: Questionnaire items to evaluate perceived security risk

\begin{tabular}{l|l} 
Item Code & Questionnaire Item \\
\hline PS1 & I think that owning bitcoins has security risks. \\
\hline PS2 & I think that using bitcoins has security risks. \\
\hline
\end{tabular}

\section{BIOGRAPHIES}

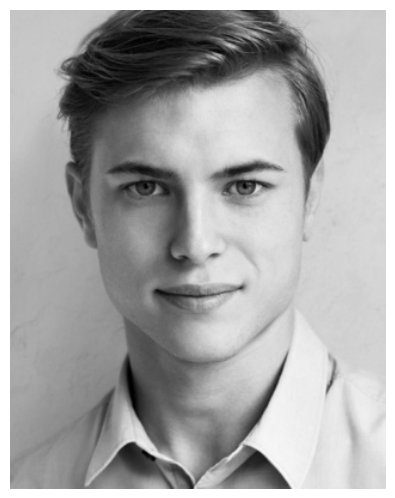

Aiden Walton holds a Bachelor of Business Science degree, specializing in Information Systems, from the University of Cape Town. His main areas of interest are automation and cryptocurrency. He currently works as a Software Engineer in the Insurance industry.

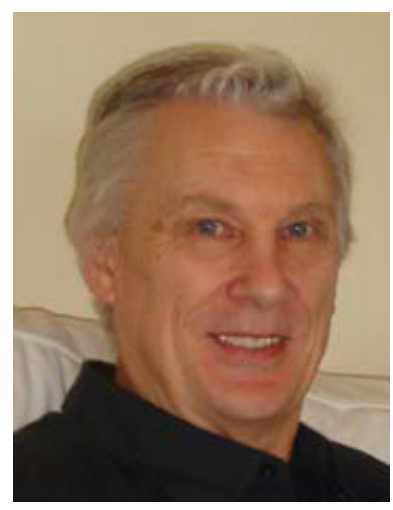

Kevin Johnston is a Professor in the Department of Information Systems at the University of Cape Town, South Africa and a visiting Professor at the University of Pforzheim, Germany. He holds a PhD in Information Systems. His principal research areas are ICT strategy and management, IS educational issues, Social and Networking systems, Emerging technology, and Entrepreneurship. 